\title{
O desvelar da verdade e a compreensão da realidade: desde a Hermenêutica Histórica de Gadamer à Análise do Discurso de Foucault
}

\author{
The unveiling of truth and understanding of reality: from the \\ Hermeneutics of Gadamer Historical Discourse Analysis of \\ Foucault
}

El descubrimiento de la verdad y la comprensión de la realidad: de la hermenéutica de Gadamer Histórico de Análisis del discurso de Foucault

Fabio Alves Ferreira

\begin{abstract}
Resumo: Neste artigo analisamos as propostas de descobrimento da realidade a partir da hermenêutica histórica de Hans-Georg Gadamer e da análise do discurso de Michel Foucault. Para Gadamer, a verdade requer a compreensão histórica do texto, de suas origens e condições de emergência. A verdade em Foucault é resultado de processos políticos de identidades que disputam discursivamente o sentido da realidade. A realidade é discursiva e o "saber" e o "poder" são articulados em novas tecnologias de produção de subjetividades.
\end{abstract}

Palavras chave: hermenêutica histórica; análise do discurso; realidade; verdade.

\begin{abstract}
In this article we analyze the proposals of the reality from the historical hermeneutics of Hans-Georg Gadamer and Michel Foucault's discourse analysis. For Gadamer, the truth requires a historical analysis of text, its origins and emergency conditions. The "truth" in Foucault is the result of political processes of identities that discursively dispute the sense of reality. The reality is discursive and "knowledge" and "power" are articulated in new subjectivities production technologies.
\end{abstract}

Latitude, Vol. 10, no 1, pp. 06-23, 2016

DOI: https://doi.org/10.28998/2179-5428.20160101 
Fabio Alves Ferreira

Keywords: historical hermeneutics, discourse analysis, truth, reality.

Resumen: En este artículo se analizan las propuestas de la Hermenéutica Histórica de Hans-Georg Gadamer y el Análisis del Discurso de Michel Foucault. Para Gadamer, la verdad requiere una comprensión histórica del texto, sus orígenes y condiciones de emergencia. La verdad en Foucault es el resultado de procesos políticos de identidades que discursivamente se disputan el sentido de la realidad. La realidad es discursiva y "conocimiento" y "poder" se articulan en nuevas tecnologías de producción de subjetividades.

Palabras clave: la hermenéutica histórica, análisis del discurso, la verdad, la realidad,

\section{Introdução:}

A pergunta acerca do que é a verdade ecoa desde a Antiga Grécia com o método socrático maiêutico e a indução do conhece-te a ti mesmo. A verdade é um tema filosófico que tem inquietado os cientistas, tanto das ciências naturais quanto das ciências humanas. A imposição acerca de sua legitimidade foi causa de perseguições e mortes, principalmente nos antagonismos da Igreja Católica com outros conhecimentos que negassem o princípio de que a Bíblia era a única regra de fé e prática. Entretanto essas disputas seculares não impediram o hibridismo de concepções acerca da constituição da realidade.

O século XIX, e também o XX, foram marcados pela emergência de diversas teorias que tentavam explicar ou compreender a realidade. Principalmente nas ciências humanas, essas teorias tentavam responder, dentre outras questões relevantes, como a sociedade é possível. Então tivemos concepções acerca da realidade e conceitos sobre verdade: desde o Positivismo Lógico que propunha a unificação das ciências naturais e do espírito $^{1}$ e que defendia que a verdade por meio da explicação pode

\footnotetext{
${ }^{1} \mathrm{O}$ termo Ciências do Espírito foi cunhado por Dilthey para estabelecer diferença em relação às ciências da natureza. De acordo com sua teoria elementos da psique humana devem ser considerados na compreensão da realidade. Portanto o objetivo de toda ciência não é
} 
O desvelar da verdade e a compreensão da realidade: desde a Hermenêutica Histórica de Gadamer à Análise do Discurso de Foucault

somente ser constatada (BRYANT, 1985); as concepções kantianas do conhecimento a priori e do mundo fenomenal e noumenal (BENTON, 1977); até as concepções de Husserl de que a realidade é estruturada em termos de percepção e que, portanto, o mundo não existe sem subjetividade (ALEXANDER, 1992); até mesmo a concepção estruturalista de que a linguagem representa o mundo e em seguida de que o mundo é constituído pela linguagem (WITTGENSTEIN, 1979) e, ainda o pragmatismo onde a verdade é reduzida à utilidade, pois antes da experiência não existe sujeito pensante (JAMES, 1952). Todas estas teorias, e ainda muitas outras, versam de algum modo sobre a constituição do mundo e da verdade sobre ele.

Neste trabalho fizemos o recorte de dois teóricos que também desenvolveram uma teoria do conhecimento. Tentaremos explicitar os conceitos de Michel Foucault e Hans-Georg Gadamer de método, verdade e implicações na construção da realidade social. Ambos os teóricos têm se apresentado, ainda hoje, como importantes pensadores para construção do conhecimento e leitura da realidade. Desta maneira, fomos impulsionados por algumas questões, às quais esse texto tenta responder: Como se constitui a verdade para Gadamer e Foucault? Qual é o método utilizado para constatá-la? Quais as implicações de suas diferenças na produção do conhecimento? Qual o lócus por meio do qual se deve compreender a realidade? Em que ponto suas propostas se encontram e em que se contradizem?

Um texto, um evento, um fato, um discurso afinal, são sempre reflexo de práticas sociais, incrustadas num contexto, numa economia de forças dadas situacionalmente. As reverberações e mutações desse discurso em outros discursos subseqüentes podem ser percebidas como um sentido sempre a ser retomado a partir de sua gênese. Numa outra perspectiva, cada prática discursiva é entendida por sua própria potencialidade de atualização. Num primeiro momento pela perspectiva da Hermenêutica Histórica desenvolvida por Hans Gadamer e no segundo, pela Análise do Discurso de Michel Foucault.

Foucault propõe o método, arqueológico e genealógico, no qual a polissemia do discurso toma proporção na análise. Suas contradições e arestas não são reduzidas na tentativa de devolver uma linearidade, um significado que confere unidade ao discurso. Pelo contrário, a sua proposta

explicar (bem como afirmava o positivismo lógico), mas compreender. Posteriormente Gadamer se baseia no pensamento de Dilthey para desenvolver sua hermenêutica. 
Fabio Alves Ferreira

"não tem um efeito unificador, mas multiplicador" (FOUCAULT, 2004, p. 180). Para Foucault, discurso não é somente um enunciado com articulação gramatical dos termos. Discurso é entendido como aquilo que desencadeia um determinado comportamento, forja subjetividades e confere uma verdade social.

Por outro lado, Gadamer, o filósofo da hermenêutica, surge com o questionamento do método. Assim, coloca-se contra os pressupostos do Iluminismo de que a razão é suficiente na constatação do mundo, na efetivação do conhecimento, resultando na emancipação do indivíduo. Ou seja, para Gadamer o Iluminismo se equivocou, pois não considerou que a razão é contextualmente localizada e, portanto, é também, um produto histórico.

Para Gadamer o entendimento foi escravizado pelo método. Segundo ele, a hermenêutica não consiste num método, mas numa forma de compreensão que leva em consideração as experiências vividas pelo indivíduo para o alcance do entendimento, Verstehen. Herança da ciência do espírito de Wilhem Dilthey e da fenomenologia de Heidegger. A verdade, para Gadamer, é experienciada. Esta experiência ocorre quando o mundo rotinizado apresenta-se confrontado, em dúvida, incerto. No confronto entre a realidade posta e o desconhecido, ocorre a experiência hermenêutica. No ato da experiência hermenêutica a tradição, a linguagem e a estética são articuladas para produção de novo significado.

A confluência da parte e do todo tornou-se um princípio para interpretação. Além disso, a linguagem é um ponto fundamental para a hermenêutica histórica de Gadamer, já que ela é o veículo que possibilita os indivíduos acionarem os consensos histórico-culturais e, portanto, o que ele chama de experiência hermenêutica. A tradição é o intermédio para a experiência hermenêutica que se dá no diálogo entre presente e passado (LAWN, 2007, p. 74, 82). Assim sendo, já há uma clara diferença com Foucault, para quem a linguagem não é um meio de comunicação ou expressão; é constitutiva da realidade.

Em síntese, Gadamer é a favor de uma hermenêutica cuja base sustenta o passado como tempo/espaço que informa e orienta o presente. Um texto antigo tem algo a dizer na atualidade. A verdade é revelada, horizontes encontram-se e uma nova dimensão se abre. Para ele, há possibilidades infinitas já que cada horizonte pressupõe uma perspectiva. Foucault, por outro lado, considera ilegítimo utilizar o critério da 
O desvelar da verdade e a compreensão da realidade: desde a Hermenêutica Histórica de Gadamer à Análise do Discurso de Foucault

antecedência para legitimar um discurso e deslegitimar outro. Em sua perspectiva o sentido do discurso não está preso às suas condições de emergência passadas, o seu sentido, portanto é erigido por um conjunto de regras de formação comum e um marco institucional desde onde a autoridade do discurso emana. Outra diferença entre ambos os autores é que conceber um autor a um determinado discurso, ou texto na perspectiva foucaultiana, é demarcar limites no horizonte. Já para Gadamer é conferir uma verdade, porém sempre a emergir numa nova faceta em sua atualização. Foucault argumenta que a verdade é encontrada em suas condições externas de possibilidade, naquilo que fixa suas fronteiras (FOUCAULT, 2009). Por sua vez, Gadamer sustenta que a verdade ocorre na experiência hermenêutica genuína. Isto é, experiência singular, não repetitiva e nem aferida por indução.

Tanto Foucault, quanto Gadamer, se colocam à beira de uma forma tradicional de conceber seus pensamentos. O primeiro, diz acerca de si mesmo, não haver construído uma teoria. Somente um pensamento epistemológico acerca da constituição do mundo e dos indivíduos em seu interior. Em Gadamer, também não encontramos explicitamente a afirmação de um método erguido na contramão do iluminismo, a quem se propôs criticar. Entretanto, ambos os autores contribuem diretamente para uma forma diferenciada de se fazer ciência e chegar à verdade. Nos dois, a verdade nunca é um algo positivo, que está lá fora esperando ser apreendido e explicado. A verdade não é única e os procedimentos, portanto, não são universais, embora Gadamer referencie, na construção da hermenêutica filosófica, princípios universalistas. Em Foucault, a verdade é relativa, pois considera os diversos discursos que forjam os indivíduos. Já em Gadamer a verdade também é relativa porque considera a subjetividade dos sujeitos em sua construção. Diferentemente de Foucault, Gadamer abre espaço para o sujeito que, localizado estruturalmente, tem a potencialidade de dialogar com a cultura e formar novos sentidos.

A questão que nos impulsiona diz respeito à investigação da verdade. Isso que é resolvido pelo positivismo de modo indutivo e explicativo, aqui se constitui num problema, já que ambos os autores consideram a estrutura enquanto determinante do mundo, mas também um sujeito que pode desvelar (Gadamer) e dissecar os mecanismos de constituição da realidade social (Foucault). Partimos do pressuposto de que à medida que os trabalhos de Gadamer e Foucault fornecem elementos 
Fabio Alves Ferreira

para compreensão da realidade, os próprios elementos epistemológicos se constituem em caminhos. Portanto, em método ${ }^{2}$. Queremos ainda pontuar que optamos por utilizar a obra sobre História da Sexualidade de Foucault, pois concordamos que nela está contida de maneira detalhada a lógica do discurso e sua concepção de verdade. Também consideramos a Ordem do Discurso e a Arqueologia do Saber.

Queremos também esclarecer que os significantes "objeto" e "texto" - mais usualmente presentes na obra de Gadamer - são tomados como elementos de comparação com "discurso" - termo usado comumente na obra foucaultiana. Contudo, o "texto", para Foucault, é um objeto empírico, não uma categoria analítica, como em Gadamer. Nesse sentido, os compararemos à medida que sugerem um vínculo com uma possível realidade emergente.

\section{A perspectiva da realidade a partir da hermenêutica histórica de Gadamer}

O pensamento de Hans Gadamer começou a consolidar-se com base na hermenêutica fenomenológica de Martin Heidegger. Gadamer começou a especular que a realidade é compreendida a partir de experiências hermenêuticas que ocorrem com cada indivíduo no ato contínuo de conhecimento. A experiência hermenêutica por sua vez se dá no que ele chama de fusão de horizontes. Isto é, no contato com o outro e na constatação da não-familiaridade entre as partes. Três eixos são postos, por Gadamer, como mecanismos por meio dos quais a verdade é experimentada: experiência da estética, da tradição e da linguagem.

A verdade para Gadamer é desvelada. A aletheia, ou seja, algo que emergirá. Essa revelação da verdade ocorre pelo encontro com a tradição. Isso coloca em xeque a ideia de neutralidade da razão utilizada pelo interpretante. Ele é contextualmente localizado, envolvido pela história, resultado de processos culturais e, portanto, é continuador de um diálogo pré-existente. (GRONDIN, 1999, p. 194).

\footnotetext{
2 A crítica que Gadamer faz ao método diz respeito à forma similar das ciências naturais absorvidas pelas ciências humanas. Para ele a compreensão passa pela tradição (história e cultura), mas também pela subjetividade do indivíduo, na qual o diálogo entre novo e velho acontece.
} 
O desvelar da verdade e a compreensão da realidade: desde a Hermenêutica Histórica de Gadamer à Análise do Discurso de Foucault

De acordo com Bottomore e Outhwaite, na análise que fazem da hermenêutica gadameriana, a compreensão do interpretante no ato hermenêutico ocorre pela tomada da tradição como o elemento que descortina a verdade. Isso coloca em pauta a limitação do sujeito, pois a interpretação não é algo apenas de sua subjetividade, mas é necessário considerar o passado no presente. Neste sentido há o que Gadamer chama de fusão de horizontes (1996, p. 352).

Com a compreensão, o horizonte do interprete se amplia para abranger o objeto a princípio pouco familiar, e nesse processo forma um horizonte novo, ampliado. É nesse ponto, no convergir de posições inicialmente divergentes, que pode surgir o verdadeiro significado. $\mathrm{O}$ significado constitui-se na formação dialógica de um acordo. Somente nessa experiência comunicativa é que chegamos a compreender e a conhecer mais plenamente aquilo que antes permanecia como uma parte obscura do nosso pré-entendimento, do nosso horizonte inicial (BOTTOMORE e OUTHWAITE, Op. Cit. p. 352).

Para Gadamer, tudo é interpretação e isso ocorre na ação de compreensão do indivíduo em direção ao objeto interpretado. Surge, desta maneira, uma fusão de horizontes: do sujeito que interpreta e do objeto que é interpretado. Aqui tomamos o termo objeto como algo que pode ser um discurso, um evento dado antes do momento hermenêutico do indivíduo. Ainda mais, para ele, esse diálogo só é possível porque existe um préconceito, como momento reflexivo, antes do encontro entre intérprete e objeto a ser interpretado. De acordo com Gadamer, situar a tradição dentro de contextos atuais, ou fenômenos sociais contemporâneos, é o eixo medidor da verdade, para compreensão, desde uma perspectiva da ciência do espírito (GADAMER, p. 53).

Numa perspectiva da Análise do Discurso a compreensão de um texto não pressupõe a compreensão das intenções subjetivas do autor. O texto não se esgota neste desdobramento. Gadamer parte de Heidegger que sustenta a existência de uma estrutura ontológica do círculo hermenêutico. 
Fabio Alves Ferreira

Isso implica na defesa de que a nossa compreensão é condicionada por uma pré-compreensão. A historicidade de cada sujeito é, pois, uma condição de pré-compreensão: "nós compreendemos e tendemos para uma verdade, porque somos guiados neste processo por expectativas sensoriais". (GRONDIN, 1999, p. 186).

Gadamer não nega a existência de pré-concepções como artifício da negatividade da vida do objeto interpretado. Para ele, os preconceitos são condições de compreensão. Todo sujeito, pelo fato de ser concebido por processos que ocorrem dentro de uma tradição, carrega consigo um estoque de conhecimento - usamos aqui um termo da fenomenologia de Schütz - que ele acessa para compreender e elaborar novos significados (GRONDIN, 1999).

A questão do historicismo também emerge com a vigilância de que cada doutrina deve ser entendida de acordo com as forças sociais de sua época. Interpretar, compreender um discurso, analisar um texto ou fatos sociais que engendram comportamentos, não implica no distanciamento dos processos históricos. A isso Gadamer estabelece uma acirrada crítica. O historicismo sustenta um método cuja base é o afastamento dos préconceitos. Em Gadamer, esse pressuposto condiciona e limita a compreensão. (GRONDIN, 1999).

A versatilidade da hermenêutica gadameriana apresenta-se, mais uma vez, na concepção de que a experiência hermenêutica se dá por meio do questionamento constante. Isso traz consigo os pré-conceitos que podem fomentar as inquietações no encontro com o horizonte do outro. Entretanto, isso permite que o próprio texto, ou objeto interpretado, apresente suas contestações às pré-concepções do sujeito. Logo, os preconceitos, não são determinações intocáveis e nem um refúgio no qual a realidade se daria subjetivamente.

Para Gadamer a compreensão já é aplicação. Ou incidem num mesmo momento. Compreender implica num encontro do indivíduo com ele mesmo. Nesse caso, a interpretação significa uma auto-compreensão e, portanto, aplicação também. Seria a aplicação de um sentido às interrogações, impulsos e angústias que constituem o ontológico (Id. Ibid. p. 193).

$\mathrm{Na}$ perspectiva gadameriana a interpretação pressupõe uma continuidade de um diálogo que ocorreu antes de nós. Para tanto, é necessário utilizar a lógica de funcionamento da configuração de sua época 
O desvelar da verdade e a compreensão da realidade: desde a Hermenêutica Histórica de Gadamer à Análise do Discurso de Foucault

para compreendê-lo e então transpassá-lo para a contemporaneidade. Desta maneira ocorre a mudança. O texto é situado num novo contexto e novos sentidos são construídos. Um sentido é construído, porém não autonomamente, pois há uma linha bem demarcada pela história. O retorno, portanto, aponta para algo no discurso que perdura, para que sua verdade seja encontrada.

A compreensão é guiada pela linguagem. Gadamer sustenta o argumento de que a linguagem ordena o mundo. Um exemplo desenvolvido por ele é quando temos a experiência de traduzir um texto: as elucubrações que ocorrem até encontrar a palavra adequada para expressar determinada frase; as pausas que seguem este trabalho e, finalmente, o momento da eureka! Gadamer explicitamente coloca que se segue uma certeza, uma ordenação amparada na convicção de que o conhecimento da linguagem tornou objetivo, traduziu, manifestou a verdade do texto. “Quando encontramos a expressão acertada... então retomamos uma instância firme em meio ao torvelinho das coisas estranhas que se dão no acontecer da linguagem, cuja variação infinita faz com que percamos a orientação". (GADAMER, 2007, P. 267-268).

Isso é o que ele chama de experiência hermenêutica. $O$ mundo já interpretado que é atravessado pela experiência e conseqüentemente faz com que novas experiências surjam, novas compreensões e, portanto, um novo sentido. Para Gadamer não é o estranhamento o elemento primordial que desencadeia o conhecimento. É exatamente, em sua perspectiva, o assentamento no que é familiar. Uma zona de conforto, na qual as convicções do sujeito estão amparadas, facilita o trânsito do que está em torno, e desencadeia o estabelecimento do que se coloca numa posição alheia. (id. Ibid. p. 268). Para consolidar sua ideia de que os indivíduos comungam de um acordo num mundo já interpretado, ele explicita por meio do exemplo de um aprendizado de um idioma: a assimilação de um novo idioma é iniciada pelo paralelo constante na língua matriz do indivíduo, de palavras e expressões, numa tentativa de buscar sentido ao que se tenta comunicar. Quando, totalmente assimilado o idioma, estabelece-se uma zona de conforto, na qual este constante retorno mental deixa de existir. Não é necessária mais uma comparação, um ajuntamento de sentidos entre os dois idiomas. $\mathrm{O}$ mundo apresenta-se a esse estrangeiro como interpretado. 
Fabio Alves Ferreira

Finalmente, Gadamer enfatiza que a experiência hermenêutica se dá no limiar de um horizonte e encontro com outro. Quando questões são levantadas e o novo significado apresenta-se como resposta. Quando o mundo interpretado aparece em sua contingência há a necessidade de uma ampliação de seu horizonte. Assim é que o objeto à margem desse mundo significativo para o sujeito interpretante é chamado à vida e a verdade é revelada. Nesse caso, ocorre um redimensionamento das extremidades de seu mundo de significado e uma fusão de horizontes dá o tom de uma nova e ampla compreensão.

\section{A verdade e método em Foucault}

Para Michel Foucault a produção e a manutenção de um discurso são sempre institucionais. Desta forma, desvendar e compreender a fluência e rigidez de um discurso é facilitado pela operacionalização do poder. O discurso, portanto, é resultado de uma relação de poder. Nesse caso, na perspectiva foucaultiana a verdade tem uma relação ontológica com o poder. Para melhor entender esta lógica, partimos da definição de discurso de Foucault.

...gostaria de mostrar que o discurso não é uma estreita superfície de contato, ou de confronto, entre uma realidade e uma língua, o intrincamento entre um léxico e uma experiência; gostaria de mostrar, por meio de exemplos precisos, que, analisando os próprios discursos, vemos se desfazerem os laços aparentemente tão fortes entre as palavras e as coisas, e destacar-se um conjunto de regras, próprias da prática discursiva. (...) não mais tratar os discursos como conjunto de signos (elementos significantes que remetem a conteúdos ou a representações), mas como práticas que formam sistematicamente os objetos de que falam. Certamente os discursos são feitos de signos; mas o que fazem é mais que utilizar esses signos para designar coisas. É esse mais que os torna irredutíveis à língua e ao ato da fala. É esse "mais" 
O desvelar da verdade e a compreensão da realidade: desde a Hermenêutica Histórica de Gadamer à Análise do Discurso de Foucault

que é preciso fazer aparecer e que é preciso descrever. (FOUCAULT, 1986, p.56)

Na história da sexualidade 1: a vontade de saber (2003), Foucault explicita essa lógica de aferição da verdade por meio de discursos legitimadores do conhecimento. Desde o século XVII, no início da repressão sexual, houve uma manipulação da linguagem para que houvesse também uma instrumentalização do discurso. $\mathrm{O}$ repertório de palavras utilizadas para designar o sexo mudou de foco. Baniram-se termos e alocaram-se outros, estes últimos, cheios de pudor, de contenção moral, de valores que imprimiam um modo recalcado (interdito) de tratar as questões de teor sexual.

Foucault sustenta a ideia de que houve uma ampla discursividade sobre o sexo. Entretanto essa discursividade aconteceu de forma disciplinarizada. Isto é, foram desenvolvidos diversos mecanismos, primeiro por meio da Igreja Católica e posteriormente pelo aparecimento de vários campos do conhecimento científico, que pretendiam reafirmar uma verdade sobre o sexo. Para desvendar como se deu essa construção da positividade sobre o sexo, Foucault propõe o método de análise do discurso: quem fala sobre o sexo? O que se fala sobre ele? Qual o lugar social daquele que fala sobre sexo? Quem armazena o seu conhecimento e o difunde?

Esse regramento do discurso, vinculado a um saber institucionalmente reconhecido desde onde a verdade emana, aconteceu também com a construção social do louco. Foucault, por meio da análise da loucura, bem como da sexualidade, explicita como se ergueram campos do conhecimento que disciplinarizaram os corpos. A isso ele chama a vontade de verdade (FOUCAULT, 2009).

Para Foucault, claramente houve uma incitação ao discurso do sexo. Entretanto essa incitação discursiva era regulada. As falas, e as permissividades, deviam acontecer por meio de instituições que autorizavam o discurso. Numa primeira fase Foucault chamou de o dispositivo da aliança. E num momento posterior dispositivo da sexualidade.

O primeiro refere-se aos mecanismos empreendidos pela religião no século XVII. Ele aponta para a expansividade que o sexo assumiu por meio da elaboração de um discurso. Um exemplo disso é visto na atuação da 
Fabio Alves Ferreira

Igreja Católica que instigou a confissão, como forma de se falar das coisas secretas, do sexo. Já o dispositivo da sexualidade ocorreu pela substituição do centro: os mecanismos de controle do corpo são discursivamente sofisticados. Então surge a medicina, a psiquiatria, a psicologia, a pedagogia como formas institucionalizadas de poder, que classificaram, nomearam e estabeleceram muros em torno do sexo. Desta maneira desenvolveram conhecimentos positivistas no qual prescindia uma forma correta de exercer a sexualidade e desnudar o corpo.

Nesses novos mecanismos de controle, a confissão ainda vigora. Espaço no qual alguém fala de si mesmo. Entretanto no ato de confessar, não há uma aproximação dos prazeres e construção de uma autonomia em relação ao desbravamento dos lugares do humano, das descobertas de si. Aquele que fala, que responde e que analisa a si mesmo é na verdade aquele que se submete, que se constrange, que se torna vulnerável e impreciso. Nesse caso a instituição religiosa legitimada pelo conhecimento supostamente "coeso" e das sensações e experimentações do sexo daria a precisão no qual deveriam ocorrer as intimidades dos casais heterossexuais. A confissão, portanto, é colocada por Foucault como aquela que rege a produção do discurso sobre o sexo. Essa confissão teve implicações em todos os outros mecanismos que se desenvolveram no século XIX.

A confissão difundiu amplamente seus efeitos: na justiça, na medicina, na pedagogia, nas relações familiares, nas relações amorosas, na esfera mais cotidiana e nos ritos mais solenes; confessam-se os crimes, os pecados, os pensamentos e os desejos, confessam-se passado e sonhos; confessa-se a infância; confessam-se as próprias doenças e misérias; emprega-se a maior exatidão para dizer o mais difícil de ser dito; confessa-se em público, em particular, aos pais, aos educadores, ao médico, àqueles a quem se ama; fazem-se a si próprios, no prazer e na dor, confissões impossíveis de confiar a outrem, com o que se produzem livros. (FOUCAULT, 2003, p. 59). 
O desvelar da verdade e a compreensão da realidade: desde a Hermenêutica Histórica de Gadamer à Análise do Discurso de Foucault

As considerações de Foucault explicitadas na história da sexualidade mostram-nos a lógica por meio da qual o discurso é operacionalizado. Embora ele trate do controle do corpo e dos mecanismos que permitiram o exercício exemplar deste controle, o texto aponta a estrutura do discurso e a construção da verdade. Nesse caso, a verdade é exógena ao indivíduo, determinada por instituições que detêm o conhecimento legítimo. Por meio do discurso essa verdade é difundida por mecanismos que penetram em instâncias mais particulares dos indivíduos e imprimem o modo de manifestarem os seus corpos na sociedade.

O discurso em Foucault deve ser tomado em sua positividade. Isto é, interessa menos a sua origem e por outro lado há uma importância das regras de seu funcionamento: o acentuado interesse em quem estabelece as regras e autoriza o seu funcionamento. Isto é, quem define a lógica de seu funcionamento e em quais situações (SALES, 2008). Desta maneira, para entender como se dá a construção social da realidade, em Michel Foucault, é necessário tanto a perscrutação arqueológica, quanto a ideia de uma genealogia.

O legado arqueológico, na proposta de Foucault, é a marginalidade do conteúdo dos discursos, das representações a que ele se remete. Com a arqueologia o discurso é entendido a partir dele próprio. A análise não busca um discurso por trás do discurso. A área do conhecimento que se propõe a isso é a hermenêutica histórica gadameriana que pressupõe uma verdade profunda que é incorporada como auto-compreensão em nosso cotidiano (DREYFUS e RABINOW, 1995). Seu postulado é a interpretação do discurso com o fim de entender o seu significado. De outro lado, Foucault explicita que para a proposta da arqueologia do saber, as contradições não são tomadas como enigma que devem ser decifrados para compreensão do todo. São objetos a serem descritos por si mesmos (FOUCAULT, 2004).

Desse modo, em síntese, o método arqueológico consiste em: (i) procura descontinuidades; (ii) há uma historicidade dos saberes sobre o ser humano; (iii) os discursos disseminam saberes que em seu interior estão regulados. Já no método da genealogia do poder, a ênfase está nas relações de poder estabelecidas no embate/controle entre discursos, objetos, instituições, indivíduos no interior da sociedade. Assim, diríamos, inicialmente que ambos os métodos se complementam. E, em síntese, a genealogia consiste em; (i) o poder não é localizável (não está no Estado, 
Fabio Alves Ferreira

por exemplo); (ii) não é universal, pois se dá dentro de regras específicas de funcionamento; (iii) é difuso; (iv) o poder se institui pela produção do saber;

A genealogia, assim como a arqueologia do saber, se contrapõe ao método histórico de que há uma continuidade e de que o objeto remete a um mundo de significado por trás de si. A genealogia destaca as descontinuidades como algo significativo em si mesmo. Rabinow sustenta que Foucault, por meio da genealogia, reafirma que a gênese das coisas não tem primazia alguma. Que não existe essa transcendência ao discurso que o explica, o define e o interpreta com coesão (DREYFUS e RABINOW, 1995).

Foucault mostra que a tendência é imaginar que no começo das coisas está a perfeição. Um tempo fora do tempo, no qual as coisas se originaram a partir de uma criação divina. Em outras palavras, há uma tendência a mitificar e absolutizar o início contando em seguida a degradação dos tempos seguintes (FOUCAULT, 2000).

Não há um fato transcendente ao discurso que o explica e que tem a verdade sobre ele. Mas a lógica proposta por Foucault é a imanência do texto, do discurso, do objeto. Ele é o significado dele mesmo. Não há uma filiação e nem mesmo um mito fundador que apreende todo o discurso. As rupturas são os fatos que interessam à genealogia. Como o próprio Foucault diz, a genealogia se opõe ao aspecto metahistórico da história. Ou seja, o objeto remete-nos a uma realidade subjacente a ele; que encontrar a verdade é retomar personagens ou acontecimentos que não aparecem no objeto, ou no discurso, ou no texto, mas que, contudo, são fundamentais para seu entendimento (Id. Ibid).

Entender o discurso em Foucault, a partir da arqueologia e genealogia, coloca-nos para além do binarismo entre o original e o repetitivo, entre o novo e o velho, entre a regularidade e a dispersão. Para ele, o discurso é a regularidade na dispersão. Isto é, a irregularidade em suas próprias palavras não designa o desviante, o marginal, o retardatário ou mesmo o profético. Isso seria um positivismo do qual Foucault declina. Seria prescindir uma coerência, negada pelo próprio conceito de arqueologia. Nesse caso, a regularidade melhor se refere "ao conjunto das condições nas quais se exerce a função enunciativa que assegura e define sua existência". (FOUCAULT, 2002, p. 165).

É explícito o argumento de que todo enunciado é portador de uma regularidade que se contrapõe a outras regularidades. Isto é, a outras práticas discursivas. Desta maneira, está posto o significado de que um 
O desvelar da verdade e a compreensão da realidade: desde a Hermenêutica Histórica de Gadamer à Análise do Discurso de Foucault

discurso consiste numa regularidade na dispersão. Ou seja, na pluralidade discursiva produzida numa sociedade, o discurso se reafirma por regras ditas desde um lugar no qual a verdade e o conhecimento do outrem são melhor conceituados por quem produz o discurso.

O que busca nos textos de Lineu ou de Buffon, de Petty ou de Ricardo, de Pinel ou de Bichat, não é estabelecer a lista dos santos fundadores; é revelar a regularidade de uma prática discursiva que é exercida, do mesmo modo, por todos os seus sucessores menos originais, ou por alguns de seus predecessores..." (FOUCAULT, 2002, P. 166).

O modo como essa regularidade é produzida em diferentes cenas enunciativas é um ato de investigação proposto Michel Foucault. Não perscrutar o sentido ontológico dos signos, mas de como a linguagem determina existências de modo diferentes. Olhar nessa perspectiva leva a aceitar que a realidade se caracteriza por ser lugar de disputa de uma diversidade de discursos sobre o sentido dessa realidade. Vê a reprodução disso nas práticas sociais, os interesses que moldam os atores e a reincidência de práticas políticas em determinadas condições semelhantes ou divergentes de outras práticas políticas dentro de outras circunstâncias.

Feita essa exposição aferimos que o método para chegar à verdade em Foucault é desconstrutivo e a verdade, que é sempre construída socialmente, está em relação amistosa com o poder. Logo a verdade é uma questão política. Ela é produzida socialmente por esses dispositivos tecnológicos de poder, que ocorrem em instância micro, mas que são legitimados pelas instituições. Nesse caso, compreensão do mundo passa pelo descamar dessas políticas sofisticadas de imposição de uma verdade.

\section{Considerações finais:}

No decorrer deste trabalho, esforçamo-nos para expor a perspectiva da hermenêutica histórica de Gadamer e a análise do discurso de Foucault. Ambos fornecem importantes caminhos para compreender a realidade e encontrar aquilo que se entende como verdade. Ambos sugerem instigantes reflexões para entendermos as relações sociais e construção do conhecimento. Sobre isso, desde já apontamos nossa maior afinidade com o 
Fabio Alves Ferreira

pensamento foucaultiano. Consideramos sua proposta complexa e que nos chama a posicionamentos éticos e normativos diante da constituição da realidade.

Foucault faz um recorte no que ele chama de enunciado discursivo e este não se reduz ao lingüístico. Entretanto este enunciado sempre se reporta à língua, por meio da lógica, e o próprio ato de análise que é um ato lingüístico. Foucault procura a sistematicidade e coloca o texto como portador de contradições. Lugar de colisão e paradigmas diferentes. Para análise do discurso o mito fundador não importa. Para entender o discurso deve-se partir da lógica imanente e não transcendente ao texto. Para Foucault um discurso é sempre o fechamento de um sentido; a verdade é sempre resultado de práticas discursivas e resultado de práticas sociais.

Uma diferença circunstancial entre Gadamer e Foucault também se encontra na definição de linguagem. Enquanto Gadamer concebe a linguagem como uma pretensão de encontrar o termo adequado, sempre incansável na tentativa de expressar os pensamentos e sentimentos; em Foucault a linguagem condiciona os pensamentos e nada é maior que ela. Os pensamentos somente são pensados dentro das estruturas fornecidas pela linguagem. Nesse sentido, ela é determinante da realidade e a verdade do mundo é construída pela linguagem. Para ele, a realidade é discursiva.

Para Foucault, todo discurso é uma tentativa de dominar o campo da discursividade. Assim comenta Ronaldo Sales: “...todo discurso é uma tentativa de dominar o campo da discursividade, deter o fluxo das diferenças, construir um centro, dizer a verdade social". (SALES, 2008, p. 156). A verdade em Gadamer é encontrada por meio da experiência singular. A verdade é experiência e, esta, consiste num insight. Um momento fortuito no qual o novo invade o mundo já interpretado do individuo e provoca questionamentos. Para Gadamer, a experiência mostra a finitude do conhecimento humano e as possibilidades infinitas em que pode ocorrer o conhecimento.

A nosso ver, desde a exposição das diferenças de compreender a realidade em Gadamer e Foucault, consideramos mais apropriado, o esforço de Foucault em diagnosticar a realidade contemporânea. Concordamos com Rabinow quando detalha a especificidade do pensamento foucaultiano em apontar relações políticas nas quais os sentidos são cortados por intervenções de um antagonismo resultado da emergência de novos dispositivos de verdade. Em seu interior é 
O desvelar da verdade e a compreensão da realidade: desde a Hermenêutica Histórica de Gadamer à Análise do Discurso de Foucault

desenvolvido mecanismos de micro-políticas nas quais os corpos, pensamentos e comportamentos são moldados. Por meio dos elementos epistemológicos de Foucault, percebemos que onde parece haver paz, há conflitos latentes e manifestações de poder.

\section{Referências Bibliográficas:}

ALEXANDER, Jeffrey. Las Teorias Sociológicas desde La segunda guerra mundial: análisis multidimensional. Barcelona: Gedisa, 1992.

BENTON, Ted. Philosophical Foundations of the Three Sociologies. Londres/Henley/Boston: Routledge e Kegan Paul, 1977.

BRYANT, Christopher. Positivism in Social Theory and Research. Hampshire e Londres: MacMillan, 1985.

FOUCAULT, Michel. A ordem do discurso: aula inaugural no Collège de France, pronunciada em 2 de dezembro de 1970. 18ª ed. São Paulo: Edições Loyola, 2009.

A verdade e as formas jurídicas. $3^{\mathrm{a}}$ ed. Rio de Janeiro: NAU Editora, 2003.

História da sexualidade 1: a vontade de saber. 15ª ed. São Paulo: Graal, 2003.

2002

A arqueologia do saber. $6^{\underline{a}}$ ed. Rio de Janeiro: Forense Universitária,

A arqueologia do saber. $7^{a}$ ed. Rio de Janeiro: Forense Universitária, 2004.

GADAMER, Hans-Georg. Verdade e método II: complementos e índice. $3^{\mathrm{a}}$ ed. Petrópolis: Vozes, 2007.

GRONDIN, Jean. Introdução à hermenêutica filosófica. São Leopoldo: Unisinos, 1999.

JAMES, William. The Principles of Psychology. Great Books of the Western World. Chicago, Londres, Toronto e Genebra: Encyclopaedia Brittanica, 1952.

LAWN, Chris. Compreender Gadamer. Petrópolis: Vozes, 2007.

RABINOW, Paul; DREYFUS, Hubert. Michel Foucault, uma trajetória filosófica: para além do estruturalismo e da hermenêutica. Rio de Janeiro: Forense Universitária, 1995. 
Fabio Alves Ferreira

SALES, Ronaldo. Laclau e Foucault: desconstrução e genealogia. In: MENDONÇA, Daniel; RODRIGUES, Léo Peixoto (Orgs). Pós-Estruturalismo e Teoria do Discurso: em torno de Ernesto Laclau. Porto Alegre, 2008, p. 145 163.

WITTGENSTEIN, Ludwig. Investigações filosóficas. Os Pensadores. São Paulo: Victor Civita, 1979.

Enviado em 07/03/2016

Aceito em 15/07;2016 